\title{
Genomics firms turn to other markets
}

The democratization of genomics looks set to accelerate. Next week, at the annual Advances in Genome Biology and Technology meeting in Marco Island, Florida, genomics companies will still be concentrating on impressing the large sequencing centres, their most high-profile customers.

But some also want to entice buyers in individual labs and in other disciplines of science - by promising to deliver new kinds of data faster, and by making them easier to analyse. Next-generation machines could bring certain research goals, such as rapidly sequencing disease-causing microbes, closer.

'Second-generation' platforms, which quickly read out huge data sets made up of short pieces of DNA, have delivered most of the gains so far. The cost to use such technologies to sequence a million bases of DNA dropped from US\$5 in 2008 to \$2 last year to about $\$ 1$ now, and will drop under \$1 by the end of this year, says Chad Nusbaum, co-director of the genome-sequencing and analysis programme at the Broad Institute in Cambridge, Massachusetts.
The trend of more reads at lower cost will continue. Last month, industry heavyweight Illumina of San Diego, California, promised to unveil a second-generation machine capable of sequencing a whole human genome for $\$ 10,000$ over eight days. Its major competitor, Life Technologies of Carlsbad, California, has promised to upgrade its existing system to sequence a human genome for $\$ 3,000$.

But this fast, cheap sequencing comes with the challenge of storing, processing and analysing large amounts of data, mostly in the form of myriad short-sequence fragments. "The constant trajectory upwards is great for labs like ours, but the companies may be leaving people behind who don't want to generate a billion reads," says Elaine Mardis, co-director of the genome-sequencing centre at Washington University in St Louis, Missouri.

That's the apparent motivation behind Illumina's announcement that it will begin selling a 'lite' version of its existing platform

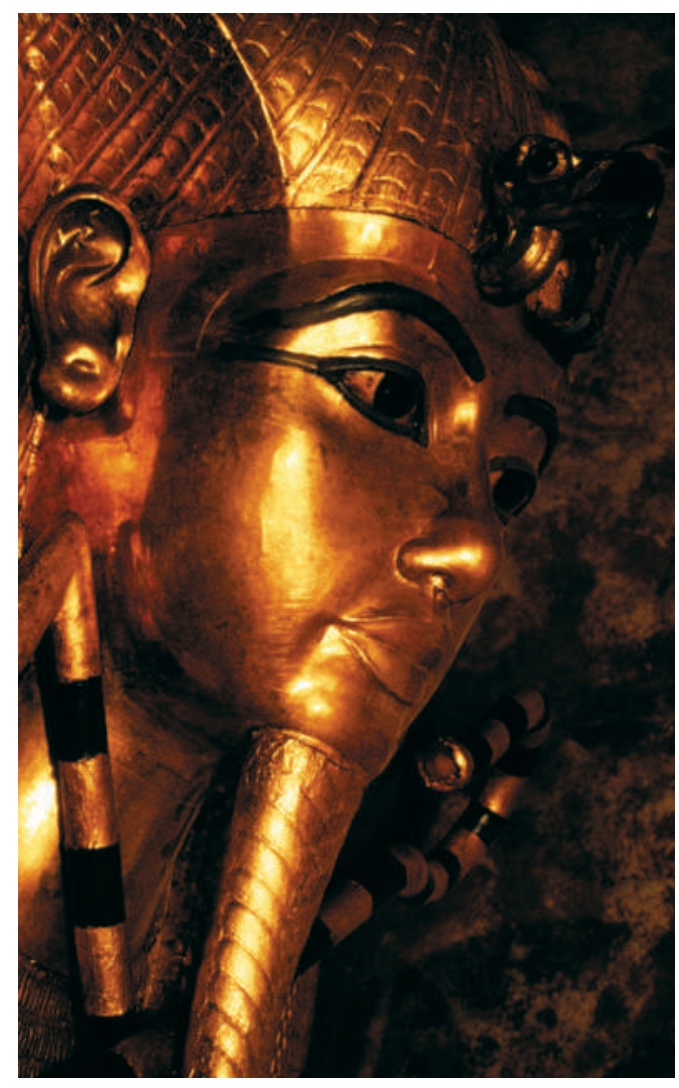

\section{SNAPSHOT Pharaoh puzzle}

A research team thinks it has solved the mystery surrounding the death of Egyptian 'boy king' Tutankhamun, who died in about 1324 BC aged just 19.

Imaging results suggest that

Tutankhamun had osteonecrosis of two bones in one foot, and DNA evidence suggests he was infected with the malaria parasite Plasmodium falciparum. These factors, combined with a leg fracture - perhaps resulting from his foot problems - may have led to his death, asserts the team led by Zahi Hawass, head of Egypt's Supreme Council of Antiquities in Cairo.

Several outside experts, however, are sceptical, and say that the paper's conclusions overstep its data.

Genetic fingerprinting done on Tutankhamun and ten other mummies has also yielded a putative fivegeneration family tree (Z. Hawass et al. J. Am. Med. Assoc. 303, 638-647; 2010). See go.nature.com/c7dFly for more.

Declan Butler
— one that costs less and delivers fewer data per run - this quarter.

Other companies, including Oxford Nanopore Technologies in Oxford, UK, and Life Technologies, are at work on 'thirdgeneration' technologies, which read out long, continuous stretches of DNA as it is being sequenced. Pacific Biosciences of Menlo Park, California, will start shipping its first such machines later this year. The company is positioning its machine as one that can tackle problems that are difficult to address with existing technologies, such as

rapidly sequencing microbes.

For instance, at the Florida meeting, Eric Schadt, Pacific Biosciences's chief scientific officer, will present data from multiple strains of a hydrogen-producing bacterium, Rhodopseudomonas palustris, that the company sequenced in collaboration with Caroline Harwood, a microbiologist at the University of Washington in Seattle. The goal: to unravel the genes underpinning how different strains produce different amounts of hydrogen, so that the bacterium might be engineered to produce more of the gas.

Hugh Martin, chief executive for Pacific Biosciences, adds that sequencing diseasecausing pathogens quickly would allow scientists to diagnose an infection or track its evolution. And reading long sequences of DNA would help scientists to assemble the DNA of plants or pests, whose genomes can be complex or only distantly related to those of other organisms that have already been sequenced.

"We think these areas will benefit from the advent of third-generation sequencing," Martin says.

Companies are also trying to broaden their customer base by making the data easier to manage, for instance, by allowing their customers to use cloud computing computational power distributed over the Internet - to analyse data generated locally. Big genome centres such as the Wellcome Trust Sanger Institute in Hinxton, UK, and the Washington University Genome Center have also explored partnerships with cloudcomputing networks.

Such developments could change the face of sequencing, says Mardis. "The field could open up to lots of different groups," she says, "and that's really exciting."

Erika Check Hayden 